\title{
False hearing loss in otitis externa: two case reports
}

\begin{abstract}
Otitis externa may affect middle ear or inner ear in some patients due to prolongation of disease, diabetes and labyrinthitis and result in conductive, sensorineural, or mixed hearing loss. But there may be false hearing loss in some cases, which is dealt with in this study.
\end{abstract}

Keywords: otitis externa, false hearing loss, conductive, sensorineural
Volume 2 Issue 4 - 2015

\author{
Alireza Bina,Atoosa Shahdi, Majid Mazaheri \\ Atieh Hospital, Audiology Clinic, Iran
}

Correspondence: Alireza Bina, Atieh Hospital,Audiology Clinic, Iran,Tel 817-666-2926, Email bina_alireza@yahoo.com

Received: January 27, 2015 | Published: April 14, 2015

\section{Introduction}

Materials of this report do not apply to those patients with otitis media following otitis externa or the patients with labyrinthitis and sensorineural hearing loss following otitis externa. ${ }^{1}$ In otitis externa, when there is severe external auditory canal inflammation, we witness false hearing loss. False hearing loss is caused at high frequencies due to Standing Wave Effect. In audiometry, beep does not enter the ear well through headphone and we see false hearing loss. Insert headphones are better for these patients, but when there is severe inflammation, false hearing loss is likely even by insert headphones. In severe auditory canal inflammations, it is not possible to perform otoscopy in some cases and tympanometry is helpful in such patients. ${ }^{2}$

Otitis externa in diabetic patients may become malignant Thus, accurate audiometric and tympanometric tests are of special importance. Presence of Type An tympanogram and present reflex, especially IPSI, and conductive hearing loss in audiometry means inconsistency between audiometry and tympanometry, so it should be explained to the treating physician that conductive hearing loss is false and due to severe auditory canal inflammation. Case report 1 exemplifies this case. ${ }^{3}$

\section{Case report I}

An adult man with chronic otitis externa in left ear, complaining of severe itching referred to our clinic. The patient had no otalgia. ${ }^{4}$ Otoscopy of left ear was not possible due to severe inflammation and there was a verruca-like protrusion in the patient's auditory canal. The patient stated that he had this verruca in auditory canal following this disease. The patient had problem for long time. Unfortunately, he had not referred to physician due to fear, and the patient's family forced the patient to refer to our clinic for treatment. ${ }^{5}$ Otoscopy of right ear showed normal tympanic membrane, and the patient had no compliant of the right ear. Tympanometry in both ears were Type and IPSI reflex was present in both ears.

In audiometry, right ear indicated normal hearing, but there was conductive hearing loss at high frequencies in the left ear- air bone gap at high frequencies. Audiometric and diapasonic Weber tests were lateralized towards left ear due to occlusion effect caused by auditory canal inflammation. There was an inconsistency between audiometry and tympanometry, and severe inflammation of left auditory canal caused this false hearing loss. ${ }^{6}$

In conductive hearing loss, acoustic reflex is absent. In this patient, acoustic reflex was present at $500 \mathrm{~Hz}, 1 \mathrm{KHz}, 2 \mathrm{KHz}$ and $4 \mathrm{KHz}$, which was very sharp (Figure 1).

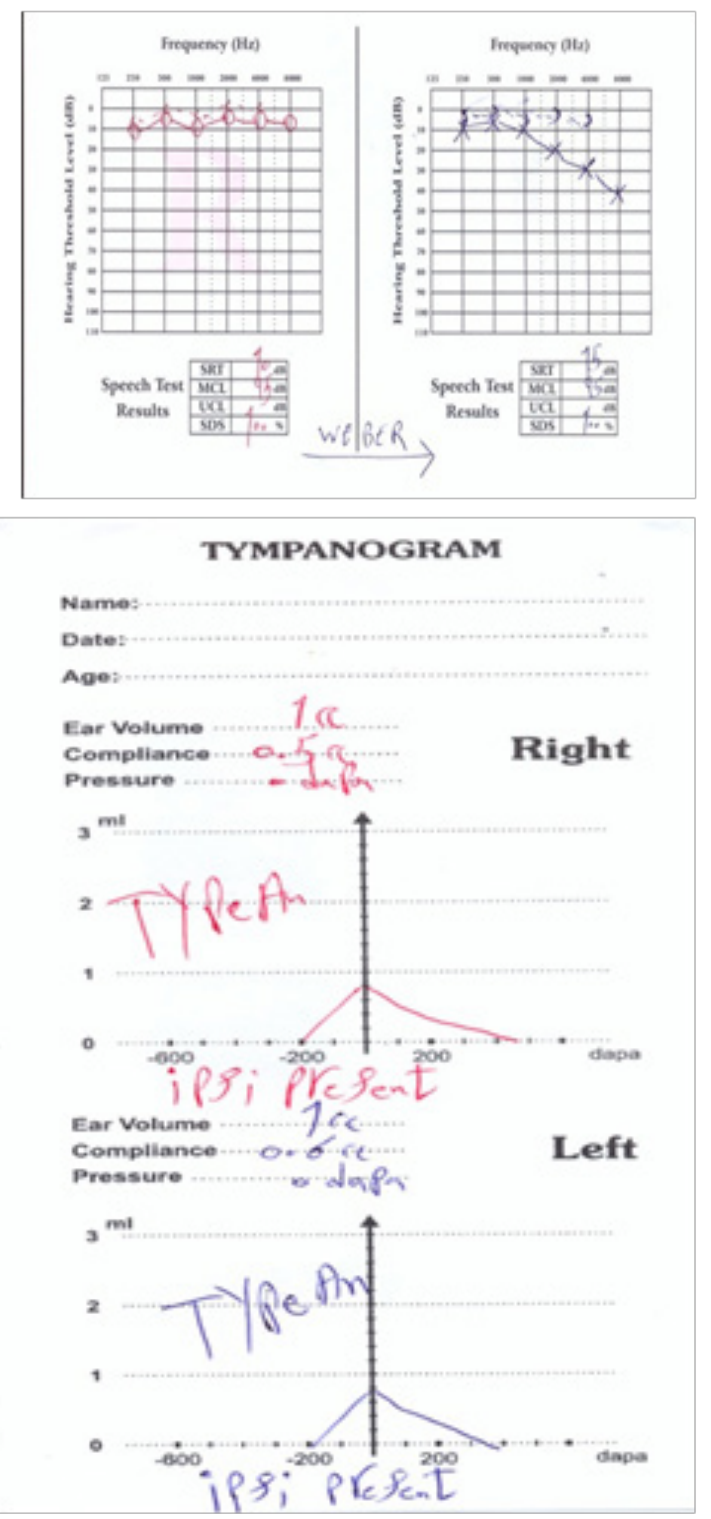

Figure I Audiogram and Tympanogram of Case No I 


\section{Case report 2}

An adult patient with chronic otitis externa in right ear, referred to out clinic, complaining of itching in right ear. The patient has no complaint in left ear. Otoscopy of left ear indicated normal tympanic membrane, but otoscopy of right ear was not possible due to severe auditory canal inflammation. ${ }^{7}$

Tympanometry was Type An in both ears and acoustic reflex was present in both ears. In audiometry, left ear indicated normal hearing, but there was sensorineural hearing loss at high frequencies

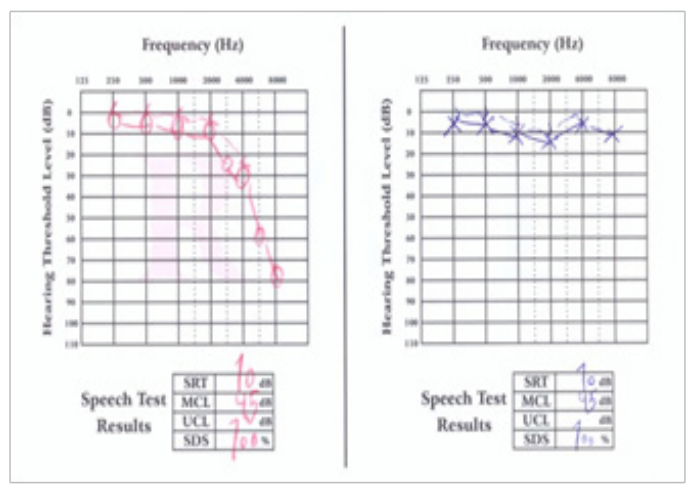

Figure 2 Audiogram and Tympanogram A2

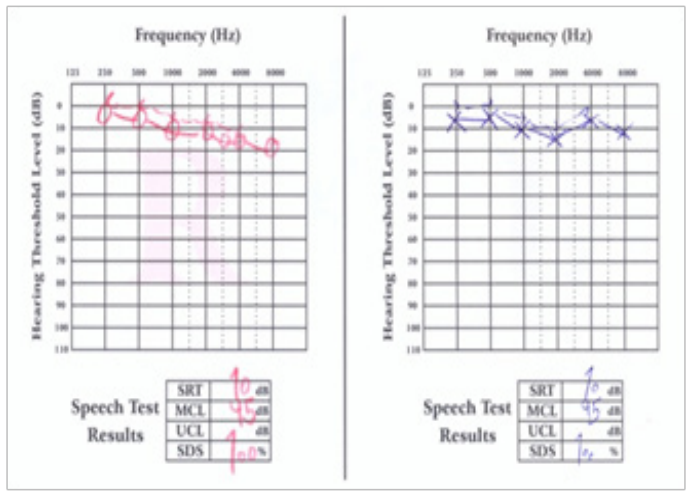

Figure 3 Audiogram and Tympanogram B2. in right ear (Audiogram A2) (Figure 2). Audiometry was performed by conventional headphones (TDH39). Audiometry was repeated by insert headphones. In second audiometry, there was no sensorineural hearing loss at high frequencies (Audiogram B2) (Figure 3). Sensorineural hearing loss at high frequencies has been caused due to Standing Wave Effect.

It is very important to identify it. In this case, if false hearing loss is not diagnosed, the physician considered that false hearing loss is due to labyrinthitis following otitis externa by mistake. ${ }^{8,9}$
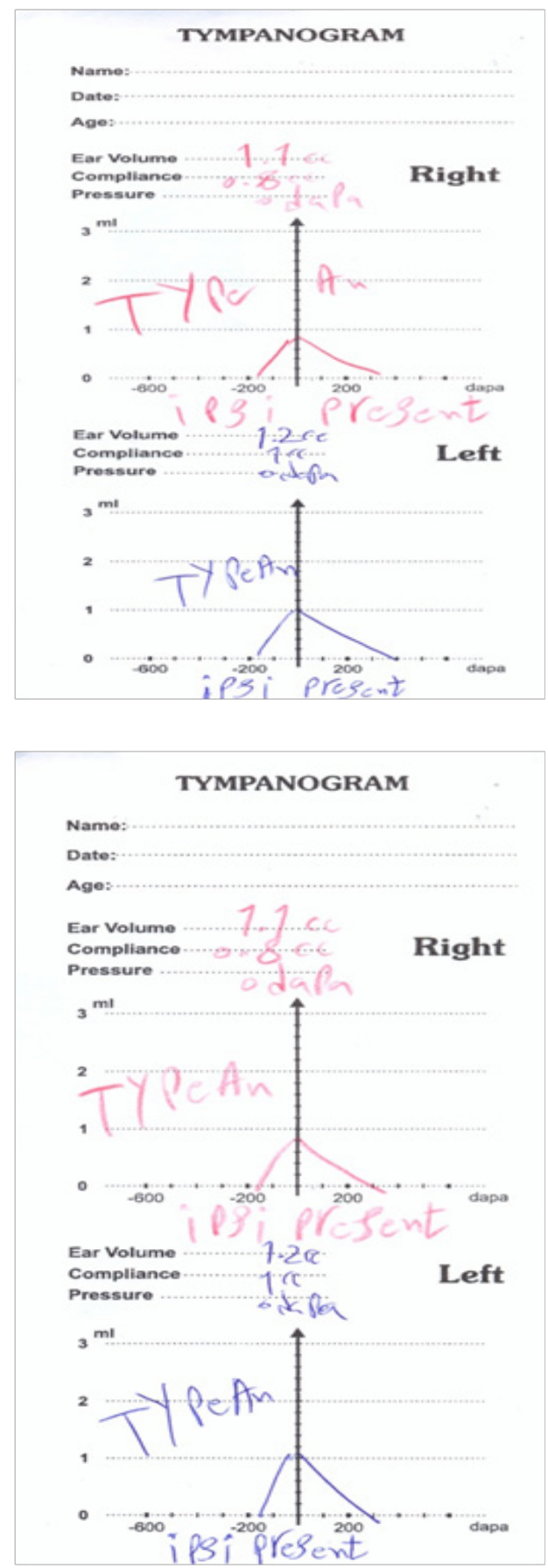


\section{Conclusion}

History taking, otoscopy, tympanometry, acoustic reflex, audiometry, and diapasonic tests (Rinne and Weber) should be consistent and the audiologist should interpret all tests with each other.

\section{Acknowledgments}

None.

\section{Conflicts of interest}

The authors declare that there are no conflicts of interest.

\section{Funding}

None.

\section{References}

1. Helen C, Mandal LH, Iversen OG. Identification of Infectious Pseudomonas aeruginosa Strains in an Occupational Saturation diving Environment. Occup Environ Med. 1998;55(7):480-484.
2. Thalmann ED. A Prophylactic Program for the Prevention of Otitis Externa in Saturation Divers. Navy Experimental Diving Unit, 1974.

3. Zichichi L, Asta G, Noto G. Pseudomonas aeruginosa Folliculitis After Shower/Bath Exposure. Int J Dermatol. 2000;39(4):270-273.

4. Roland PS, Stroman DW. Microbiology of Acute Otitis Externa. Laryngoscope. 2002;112(7 Pt 1):1166-1177.

5. Doc Vikingo. Swimmers Ear- Additional Advice about a Pesky and Sometimes Painful Problem. Issue of Alert Diver magazine, 2007.

6. Saxby A, Barakate M, Kertesz T, et al. Malignant Otitis externa: Experience with Hyperbaric Oxygen Therapy. Diving Hyperb Med. 2010;40(4):195-200.

7. Van Balen FA, Smit WM, Zuithoff NP, et al. Clinical Efficacy of Three Common Treatments in Acute Otitis Externa in Primary Care: randomized Controlled Trial. BMJ. 2003;327(7425):1201-1205.

8. Ross J Roeser, Michael valente, Holly Hosford-Dunn. Audiology: Diagnosis. $2^{\text {nd }}$ edn, Germany: Thieme publishers; 2008.

9. Jack katz. clinical audiology. In: Larry Medwetsky, Robert Burkard, Linda $\mathrm{J}$ hood, Editors, Handbook of clinical audiology. $6^{\text {th }}$ edn. USA: Wolters kluwer, Lippincott ,Williams \& Wilkins; 2009. 